\title{
Clinical Survival Predictors in Patients with Advanced Cancer Referred to an Egyptian Oncology Palliative Care Unit
}

\author{
Khaled M. Galal ${ }^{1}$ and Elia Fouad ${ }^{2}$ \\ ${ }^{1}$ Radiotherapy and Oncology Center (NEMROCK), Cairo University, ${ }^{2}$ Oncology Center, Sohag \\ University.
}

Background: Prognostication in advanced cancer allows patients to make more informed decision regarding treatment options and facilitates timely resolution of end-of- life issues.

Patients and Methods: One hundred evaluable advanced or metastatic malignant cases were divided according to PPI scoring system. Group 1 with a low PPI $\leq 4$, group 2 with intermediate PPI $>4$ and $\leq 6$ and group 3 with a high PPI $>6$. Overall survivals with Kaplan-Meier and log-rank test were estimated according to PPI and different patient and clinical predictors of survival. Positive predictive value and odds ratio was used to describe diagnostic accuracy of survival predictors.

Results: Median survivals were 189.5, 97 and 62 days in patients with palliative performance status of $>60 \%$, $30-50 \%$ and 10-20\%, respectively. Patients with low, intermediate and high PPI had median survivals of 107 , 103.5 and 77 days, respectively. Dyspnea and PPI (cut off 4) had statistical significant effect on 3 and 6-weeks survivals, while palliative performance status with cut off $30 \%$ had significant effect only on 6 weeks survival. Conclusion: Dyspnea, palliative performance status and palliative prognostic index had significant predictive effect on survival of advanced malignant or metastatic palliative patients.

Key words: palliative, prognosis, advanced, metastatic, malignant. Corresponding Author: Khaled Galal Morsi

E-mail: khaledgalal2006@yahoo.com.

\section{INTRODUCTION}

Prognostication in advanced cancer has special importance. Most terminally ill patients request information about their remaining life span. In advanced phases of the disease, prognostication cannot be based on the same information as in earlier stages, when it is typically based on tumor stage ${ }^{1,2}$. Professionals are not generally willing to provide prognosis on survival, even though they are expected to do so from their clinical experience, however physicians' prediction of survival is frequently inaccurate. Prediction of survival of patients who are terminally ill has a central role in decision making by the doctors regarding treatment, place of care and timing of referral to palliative care ${ }^{3}$. In addition, the provision of an accurate estimation of prognosis allows the patient to make more informed decision regarding treatment options and facilitates timely resolution of endof- life issues ${ }^{4}$.

In order to improve clinician prognostic estimates, some groups have attempted to identify specific predictors of survival and combine these variables into prognostic scales or scores ${ }^{2,3,5}$.

One of these scoring models is the Palliative Prognostic Index (PPI) which was developed by Morita et al. in Japan ${ }^{6}$. The PPI is based on five clinical variables (Palliative Performance Scale (PPS), oral intake, edema, dyspnea at rest and delirium) which were found to predict survival independently ${ }^{6}$ (Table 1). Using the PPI score, Morita et al. split patients into three groups with significantly different survival ${ }^{6}$. Further prospective studies to evaluate the efficacy of PPI in predicting survival of terminally ill cancer patients were conducted in Japan ${ }^{7}$ and Ireland ${ }^{4}$.

Aim of the study was to examine prospectively the prognostic predictive value of some parameters including the five clinical variables that constitute the PPI and to validate the PPI in a cohort of terminally ill Egyptian cancer patients referred to a specialized palliative care unit (PCU).

\section{PATIENTS AND METHODS}

The study included incurable advanced cancer patients referred to the PCU of Kasr Al-Aini Center of Clinical Oncology and Nuclear Medicine (NEMROCK) from October, 2009 to end of December, 2009. 
Inclusion criteria included histologically or cytologically confirmed malignant tumor, evidence of advanced or metastatic malignant disease (clinical and/ or by investigations) and life expectancy $<6$ months and referral to the PCU during the study period. Excluded patients included those receiving cancer-modifying therapy and non-malignant patients referred to PCU for symptom control.

The study was designed as patients will have initial assessment with full clinical history, detailed examination regarding and review of available investigations. The parameters for which the predictive value was examined are: Age, metastases, ascites and the five parameters that constitute the PPI which are the Palliative Performance Scale (PPS), level of oral intake, edema, dyspnea at rest and delirium.

The PPS is a modification of the Karnofisky performance scale intended for evaluating patients requiring palliative care 8 . The PPS is based on six parameters (ambulation, activity, level of disease, self care, intake and conscious level) and its score ranges from " 0 " (dead) to "100" (best performance status $)^{8}$.

Patients receiving total parenteral nutrition or feeding via enterostomies were recorded as having a "normal" oral intake.

Delirium was diagnosed according to the criteria outlined in the Diagnostic and Statistical Manual of Mental Disorders, $4^{\text {th }}$ edition (DSM-IV-text revised $2000)^{9}$ as follows:

- Disturbance of consciousness (e.g. reduced clarity of awareness of the environment) with reduced ability to focus, sustain, or shift attention.

- A change in cognition such as memory deficit, disorientation, language disturbance.

- The disturbance over a short period of time (usually hours) and tends to fluctuate during the course of the day.

- Disturbance caused by a general medical condition or substance intoxication or medication use.

Delirium was judged to be absent if considered to be caused by a single medication. The subscores of the PPI parameters Table (1) were summed to give a total PPI score which ranges from 0 to 15 . Patients were divided into 3 groups according to the total PPI score. Group 1 with a PPI $\leq 4$, group 2 with a PPI $>4$ and $\leq 6$ and group 3 with a PPI $>6$.
Statistical analysis was made using the Statistical Product and Service Solutions, SPSS 15 for Windows. The overall survival time is calculated as the period from date of evaluation of the PPI parameters until death from any cause or until the date of last follow-up, at which point data were censored. Follow up of all patients was at least of a period of 6 weeks. The positive predictive value (PPV) was used to describe the diagnostic accuracy of the survival predictors. Kaplan-Meier method and logrank test were used to compare the survival distributions of patients.

\section{RESULTS}

The registry data shows that around 3500 cancer patients are referred to NEMROCK per year. Around $10 \%$ of these cases were referred to the PCU. During the study period, 103 patients were referred to the PCU. Three patients were excluded because of receiving cancer-modifying therapy with curative or palliative intent.

Patients' characteristics are shown in Table (2). The median age was 53 and the male to female ratio was $1: 1$. The most common primary cancers were breast $(22 \%)$, lung (11\%), colorectal $(9 \%)$ and liver (9\%).

Table (3) shows the median survival according to different studied variables. Analysis revealed that PPS, PPI and the presence of dyspnea or delirium had statistical significant effect on survival. Survival did not differ significantly according to age, metastases, oral intake level, ascites and edema. Figures (1 and 2) show the survival curves as a function of PPI, PPS, dyspnea, oral intake, ascites and delirium.

Table (4) illustrates the proportion of patients surviving 3 and 6 weeks according to the studied variables. PPI and presence of dyspnea had statistically significant effect on 3 and 6 weeks-survival. PPS had a significant effect on 6 weeks-survival.

Table (5) showed sensitivity, specificity, positive and negative predictive values and significant odds ratios for different variables on survival. Dyspnea at rest and PPI with cut off at 4 had significant effect on 3 and 6 weeks survival. PPS with cut off at $30 \%$ had significant effect on 6 week survival only.

Table (6) showed the accuracy of PPI in estimating 3 and 6 weeks survival in our study compared to other different studies ${ }^{4,6}$. 
Table 1: The Palliative Prognostic Index.

\begin{tabular}{lc}
\hline Variable & Partial score \\
\hline Palliative Performance Scale & 4 \\
$10-20$ & 2.5 \\
$30-50$ & 0 \\
$60>$ & \\
\hline Oral intake & 2.5 \\
Mouthfuls or less & 1 \\
Reduced but more than mouthfuls & 0 \\
Normal & \\
\hline Edema & 1 \\
Present & 0 \\
Absent & \\
\hline Dyspnea at rest & 3.5 \\
Present & 0 \\
Absent & \\
\hline Delirium & 4 \\
Present & 0 \\
Absent & \\
\hline
\end{tabular}

Table 2: Patients' characteristics.

\begin{tabular}{lc}
\hline Characteristic & n (\%) \\
\hline Age in years, median (range) & $53(19-81)$ \\
Gender & \\
Male & $48(48)$ \\
Female & $52(52)$ \\
Primary cancer & \\
Breast & $22(22)$ \\
Lung & $11(11)$ \\
Colo-rectal & $9(9)$ \\
Liver & $9(9)$ \\
Urinary bladder & $8(8)$ \\
Head \& neck & $6(6)$ \\
Metastases of unknown primary & $5(5)$ \\
Pleural mesothelioma & $5(5)$ \\
Prostate & $5(5)$ \\
Soft tissue sarcoma & $5(5)$ \\
Lymphoma & $4(4)$ \\
Pancreas & $4(4)$ \\
Others & $7(7)$ \\
\hline
\end{tabular}

Table 3: Median survival in relation to different factors.

\begin{tabular}{|c|c|c|c|c|}
\hline Factor & & $\mathbf{n}$ & $\begin{array}{c}\text { Median Survival in days (95\% Confidence } \\
\text { interval) }\end{array}$ & $P(\log$ rank $)$ \\
\hline \multirow{3}{*}{ Age (years) } & $<40$ & 16 & $115.5(79.6-150.9)$ & \multirow{3}{*}{0.5} \\
\hline & $40-60$ & 54 & $87.5(59.9-115.1)$ & \\
\hline & $>60$ & 30 & $100.5(81.3-119.7)$ & \\
\hline \multirow{2}{*}{ Metastases } & Absent & 45 & 98 (76.6- 119.4) & \multirow[b]{2}{*}{0.09} \\
\hline & Present & 55 & $92(66.6-117.4)$ & \\
\hline \multirow{2}{*}{ Dyspnea } & Absent & 79 & $102(82.5-121.5)$ & \multirow[b]{2}{*}{0.01} \\
\hline & Present & 21 & $77(49.8-104.2)$ & \\
\hline \multirow{3}{*}{$\begin{array}{l}\text { Palliative Performance } \\
\text { Scale }\end{array}$} & $\geq 60 \%$ & 14 & $189.5(123.3-255.7)$ & \multirow{3}{*}{0.0001} \\
\hline & $30-50 \%$ & 71 & $97(80.1-113.9)$ & \\
\hline & $10-20 \%$ & 15 & $62(38.1-85.9)$ & \\
\hline \multirow{3}{*}{ Oral intake } & normal & 13 & $154(77.5-230.5)$ & \multirow{3}{*}{0.11} \\
\hline & reduced & 61 & $98(80.7-115.3)$ & \\
\hline & mouthful & 26 & $80(49.5-110.5)$ & \\
\hline \multirow{2}{*}{ Ascities } & Absent & 88 & $95.5(78.6-112.4)$ & \multirow[b]{2}{*}{0.64} \\
\hline & Present & 12 & $112.5(45.3-179.7)$ & \\
\hline \multirow{2}{*}{ Delirium } & Absent & 86 & $98.5(79.7-117.3)$ & \multirow[b]{2}{*}{0.003} \\
\hline & Present & 14 & $76.5(43.8-109.2)$ & \\
\hline \multirow{2}{*}{ Edema } & Absent & 76 & $98.5(79.8-117.2)$ & \multirow[b]{2}{*}{0.15} \\
\hline & Present & 24 & $84.5(45.7-123.3)$ & \\
\hline \multirow{3}{*}{$\begin{array}{l}\text { Palliative } \\
\text { Index }\end{array}$} & Low & 54 & $107(84-130)$ & \multirow{3}{*}{0.001} \\
\hline & Intermediate & 19 & $103.5(55.9-151.1)$ & \\
\hline & high & 27 & 77 (54.5- 99.5) & \\
\hline
\end{tabular}


Table 4: Significant factors as estimates of 3-weeks and 6-weeks survival for palliative cases.

\begin{tabular}{|c|c|c|c|c|c|c|c|}
\hline Factor & & $\begin{array}{l}\leq 3 \text { weeks } \\
\text { survival }\end{array}$ & $\begin{array}{l}\text { >3weeks } \\
\text { survival }\end{array}$ & $\mathbf{P}$ & $\begin{array}{l}\leq 6 \text { weeks } \\
\text { survival }\end{array}$ & $\begin{array}{l}>6 \text { weeks } \\
\text { survival }\end{array}$ & $\mathbf{P}$ \\
\hline \multirow{3}{*}{ Age (years) } & $<40$ & $\begin{array}{c}2 \\
16.7 \%\end{array}$ & $\begin{array}{c}14 \\
15.9 \%\end{array}$ & \multirow{3}{*}{0.19} & $\begin{array}{c}3 \\
18.8 \%\end{array}$ & $\begin{array}{c}13 \\
15.5 \%\end{array}$ & \multirow{3}{*}{0.07} \\
\hline & $40-60$ & $\begin{array}{c}9 \\
75 \%\end{array}$ & $\begin{array}{c}45 \\
51.1 \%\end{array}$ & & $\begin{array}{c}12 \\
75 \%\end{array}$ & $\begin{array}{c}42 \\
50 \%\end{array}$ & \\
\hline & $>60$ & $\begin{array}{c}1 \\
8.3 \%\end{array}$ & $\begin{array}{c}29 \\
33 \%\end{array}$ & & $\begin{array}{c}1 \\
6.3 \%\end{array}$ & $\begin{array}{c}29 \\
34.5 \%\end{array}$ & \\
\hline \multirow{2}{*}{ Metastases } & -ve & $\begin{array}{c}4 \\
33.3 \%\end{array}$ & $\begin{array}{c}41 \\
46.6 \%\end{array}$ & \multirow{2}{*}{0.29} & $\begin{array}{c}5 \\
31.3 \%\end{array}$ & $\begin{array}{c}40 \\
47.6 \%\end{array}$ & \multirow{2}{*}{0.23} \\
\hline & $+\mathrm{ve}$ & $\begin{array}{c}8 \\
66.7 \%\end{array}$ & $\begin{array}{c}47 \\
53.4 \%\end{array}$ & & $\begin{array}{c}11 \\
68.8 \%\end{array}$ & $\begin{array}{c}44 \\
52.4 \%\end{array}$ & \\
\hline \multirow{2}{*}{ Dyspnea } & -ve & $\begin{array}{c}5 \\
41.7 \%\end{array}$ & $\begin{array}{c}74 \\
84.1 \%\end{array}$ & \multirow{2}{*}{0.003} & $\begin{array}{c}8 \\
50 \%\end{array}$ & $\begin{array}{c}71 \\
84.5 \%\end{array}$ & \multirow{2}{*}{0.002} \\
\hline & $+\mathrm{ve}$ & $\begin{array}{c}7 \\
58.3 \%\end{array}$ & $\begin{array}{c}14 \\
15.9 \%\end{array}$ & & $\begin{array}{c}8 \\
50 \%\end{array}$ & $\begin{array}{c}13 \\
15.5 \%\end{array}$ & \\
\hline \multirow{3}{*}{$\begin{array}{l}\text { Palliative } \\
\text { Performance Scale }\end{array}$} & $\geq 60 \%$ & $\begin{array}{c}1 \\
8.3 \%\end{array}$ & $\begin{array}{c}13 \\
14.8 \%\end{array}$ & \multirow{3}{*}{0.16} & $\begin{array}{c}1 \\
6.3 \%\end{array}$ & $\begin{array}{c}13 \\
15.5 \%\end{array}$ & \multirow{3}{*}{0.02} \\
\hline & $30-50 \%$ & $\begin{array}{c}7 \\
58.3 \%\end{array}$ & $\begin{array}{c}64 \\
72.7 \%\end{array}$ & & $\begin{array}{c}9 \\
56.3 \%\end{array}$ & $\begin{array}{c}62 \\
73.8 \%\end{array}$ & \\
\hline & $10-20 \%$ & $\begin{array}{c}4 \\
33.3 \%\end{array}$ & $\begin{array}{c}11 \\
12.5 \%\end{array}$ & & $\begin{array}{c}6 \\
37.5 \%\end{array}$ & $\begin{array}{c}9 \\
10.7 \%\end{array}$ & \\
\hline \multirow{3}{*}{ Oral intake } & normal & $\begin{array}{c}2 \\
16.7 \%\end{array}$ & $\begin{array}{c}11 \\
12.5 \%\end{array}$ & \multirow{3}{*}{0.32} & $\begin{array}{c}2 \\
12.5 \%\end{array}$ & $\begin{array}{c}11 \\
13.1 \%\end{array}$ & \multirow{3}{*}{0.2} \\
\hline & reduced & $\begin{array}{c}5 \\
41.7 \%\end{array}$ & $\begin{array}{c}56 \\
63.6 \%\end{array}$ & & $\begin{array}{c}7 \\
43.8 \%\end{array}$ & $\begin{array}{c}54 \\
64.3 \%\end{array}$ & \\
\hline & mouthful & $\begin{array}{c}5 \\
41.7 \%\end{array}$ & $\begin{array}{c}21 \\
23.9 \%\end{array}$ & & $\begin{array}{c}7 \\
43.8 \%\end{array}$ & $\begin{array}{c}19 \\
22.6 \%\end{array}$ & \\
\hline \multirow{2}{*}{ Ascities } & -ve & $\begin{array}{c}10 \\
83.3 \%\end{array}$ & $\begin{array}{c}78 \\
88.6 \%\end{array}$ & \multirow{2}{*}{0.44} & $\begin{array}{c}13 \\
81.2 \%\end{array}$ & $\begin{array}{c}75 \\
89.3 \%\end{array}$ & \multirow{2}{*}{0.37} \\
\hline & $+\mathrm{ve}$ & $\begin{array}{c}2 \\
16.7 \%\end{array}$ & $\begin{array}{c}10 \\
11.4 \%\end{array}$ & & $\begin{array}{c}3 \\
18.8 \%\end{array}$ & $\begin{array}{c}9 \\
10.7 \%\end{array}$ & \\
\hline \multirow{2}{*}{ Delirium } & -ve & $\begin{array}{c}9 \\
75 \%\end{array}$ & $\begin{array}{c}77 \\
87.5 \%\end{array}$ & \multirow{2}{*}{0.22} & $\begin{array}{c}12 \\
75 \%\end{array}$ & $\begin{array}{c}74 \\
88.1 \%\end{array}$ & \multirow{2}{*}{0.17} \\
\hline & $+\mathrm{ve}$ & $\begin{array}{c}3 \\
25 \%\end{array}$ & $\begin{array}{c}11 \\
12.5 \%\end{array}$ & & $\begin{array}{c}4 \\
25 \%\end{array}$ & $\begin{array}{c}10 \\
11.9 \%\end{array}$ & \\
\hline \multirow{2}{*}{ Edema } & -ve & $\begin{array}{c}8 \\
66.7 \%\end{array}$ & $\begin{array}{c}68 \\
77.3 \%\end{array}$ & \multirow{2}{*}{0.31} & $\begin{array}{c}10 \\
62.5 \%\end{array}$ & $\begin{array}{c}66 \\
78.6 \%\end{array}$ & \multirow{2}{*}{0.17} \\
\hline & $+\mathrm{ve}$ & $\begin{array}{c}4 \\
33.3 \%\end{array}$ & $\begin{array}{c}20 \\
22.7 \%\end{array}$ & & $\begin{array}{c}6 \\
37.5 \%\end{array}$ & $\begin{array}{c}18 \\
21.4 \%\end{array}$ & \\
\hline \multirow{3}{*}{ PPI } & Low & $\begin{array}{c}2 \\
16.7 \%\end{array}$ & $\begin{array}{c}52 \\
59.1 \%\end{array}$ & \multirow{3}{*}{0.016} & $\begin{array}{c}3 \\
18.8 \%\end{array}$ & $\begin{array}{c}51 \\
60.7 \%\end{array}$ & \multirow{3}{*}{0.007} \\
\hline & Intermediate & $\begin{array}{c}5 \\
41.7 \%\end{array}$ & $\begin{array}{c}14 \\
15.9 \%\end{array}$ & & $\begin{array}{c}6 \\
37.5 \%\end{array}$ & $\begin{array}{c}13 \\
15.5 \%\end{array}$ & \\
\hline & high & $\begin{array}{c}5 \\
41.7 \%\end{array}$ & $\begin{array}{c}22 \\
25 \%\end{array}$ & & $\begin{array}{c}7 \\
43.8 \%\end{array}$ & $\begin{array}{c}20 \\
23.8 \%\end{array}$ & \\
\hline
\end{tabular}


Kasr-El-Aini Journal Of Clinical Oncology And Nuclear Medicine

Vol. 7 | No. 1-2 2011

Khaled M. Galal1 and Elia Fouad

Table 5: Accuracy and strength of different predictive factors as estimates of palliative patients' survival.

\begin{tabular}{|c|c|c|c|c|c|c|c|}
\hline \multicolumn{2}{|l|}{ Factors } & Survival & Sensitivity & Specificity & PPV & NPV & Odds ratio (CI) \\
\hline \multirow{2}{*}{\multicolumn{2}{|c|}{$\begin{array}{l}\text { Age } \\
\text { (cut off } 40 \text { years) }\end{array}$}} & 3 weeks & $83 \%$ & $16 \%$ & .12 & .88 & $0.9(0.19-4.8)$ \\
\hline & & 6 weeks & $81.3 \%$ & $15.5 \%$ & .15 & .81 & $0.8(0.2-3.2)$ \\
\hline \multirow{2}{*}{\multicolumn{2}{|c|}{ Metastases }} & 3 weeks & $67 \%$ & $47 \%$ & .15 & .91 & $1.7(0.5-6.2)$ \\
\hline & & 6 weeks & $68.8 \%$ & $47.6 \%$ & .20 & .89 & $2(0.6-6.3)$ \\
\hline \multirow{2}{*}{\multicolumn{2}{|c|}{ Dyspnea }} & 3 weeks & $58 \%$ & $84 \%$ & .33 & .94 & $7.4(2.1-26.7)^{*}$ \\
\hline & & 6 weeks & $50 \%$ & $84.5 \%$ & .38 & .90 & $5.5(1.7-17.2)^{*}$ \\
\hline \multirow{4}{*}{$\begin{array}{l}\text { Palliative } \\
\text { Performance status }\end{array}$} & \multirow{2}{*}{ cut off $60 \%$} & 3 weeks & $92 \%$ & $15 \%$ & .13 & .93 & $1.9(0.2-16)$ \\
\hline & & 6 weeks & $93.8 \%$ & $15.5 \%$ & .17 & .93 & $2.7(0.3-22.6)$ \\
\hline & \multirow{2}{*}{ cut off $30 \%$} & 3 weeks & $33 \%$ & $88 \%$ & .27 & .91 & $3.5(0.9-13.6)$ \\
\hline & & 6 weeks & $37.5 \%$ & $89.3 \%$ & .40 & .88 & $5(1.5-17.03)^{*}$ \\
\hline \multirow{2}{*}{\multicolumn{2}{|c|}{ Oral intake (normal vs. reduced or mouthful) }} & 3 weeks & $83 \%$ & $20 \%$ & .11 & .85 & $0.7(0.1-3.7)$ \\
\hline & & 6 weeks & $87.5 \%$ & $13.1 \%$ & .16 & .85 & $1.1(0.2-5.3)$ \\
\hline \multirow{2}{*}{\multicolumn{2}{|c|}{ Ascities }} & 3 weeks & $17 \%$ & $89 \%$ & .17 & .89 & $1.6(0.3-8.2)$ \\
\hline & & 6 weeks & $18.8 \%$ & $89.3 \%$ & .25 & .85 & $1.9(0.4-8.1)$ \\
\hline \multirow{2}{*}{\multicolumn{2}{|c|}{ Delirium }} & 3 weeks & $25 \%$ & $88 \%$ & .21 & .90 & $2.3(0.5-10)$ \\
\hline & & 6 weeks & $25 \%$ & $88.1 \%$ & .29 & .86 & $2.5(0.6-9.1)$ \\
\hline \multirow{2}{*}{\multicolumn{2}{|c|}{ Edema }} & 3 weeks & $33 \%$ & $77 \%$ & .17 & .89 & $1.7(0.5-6.2)$ \\
\hline & & 6 weeks & $37.5 \%$ & $78.6 \%$ & .25 & .87 & $2.2(0.7-6.9)$ \\
\hline \multirow{4}{*}{ PPI } & \multirow{2}{*}{ cut off 4} & 3 weeks & $83 \%$ & $59 \%$ & .22 & .96 & $7.2(1.5-34.9)^{*}$ \\
\hline & & 6 weeks & $81.3 \%$ & $60.7 \%$ & .28 & .94 & $6.7(1.8-25.3)^{*}$ \\
\hline & \multirow{2}{*}{ cut off 6} & 3 weeks & $42 \%$ & $75 \%$ & .19 & .90 & $2.1(0.6-7.4)$ \\
\hline & & 6 weeks & $43.8 \%$ & $76.2 \%$ & .26 & .88 & $2.5(0.8-7.5)$ \\
\hline
\end{tabular}

PPV: positive predictive value, NPV: negative predictive value, Odds ratio of survival, (CI)*: significant confidence interval as lower limit is more than 1 .

Table 6: Accuracy of PPI as estimates of survival in different studies.

\begin{tabular}{|c|c|c|c|c|c|}
\hline Survival & Study & Sensitivity & Specificity & PPV & NPV \\
\hline \multirow{3}{*}{$\begin{array}{l}3 \text { weeks survival } \\
\text { (PPI cut off } 6 \text { ) }\end{array}$} & Current study & $42 \%$ & $75 \%$ & $19 \%$ & $90 \%$ \\
\hline & Morita et al. ${ }^{[6]}$ & $83 \%$ & $85 \%$ & $80 \%$ & $87 \%$ \\
\hline & Stone et al. ${ }^{[4]}$ & $56 \%$ & $94 \%$ & $86 \%$ & $76 \%$ \\
\hline \multirow{3}{*}{$\begin{array}{l}6 \text { weeks survival } \\
\text { (PPI cut off } 4)\end{array}$} & Current study & $81.3 \%$ & $60.7 \%$ & $28 \%$ & $97 \%$ \\
\hline & Morita et al. ${ }^{[6]}$ & $79 \%$ & $77 \%$ & $83 \%$ & $71 \%$ \\
\hline & Stone et al. ${ }^{[4]}$ & $63 \%$ & $92 \%$ & $91 \%$ & $64 \%$ \\
\hline
\end{tabular}

\section{DISCUSSION}

The study was done to test the accuracy of PPI and other predictive factors of survival in Egyptian advanced malignant patients referred to palliative oncology unit.

Certain clinical signs and symptoms have proven to be prognostically significant, the most important of which are performance status, cancer anorexia-cachexia syndrome, dyspnea and delirium or cognitive failure. Factors linked to the patient or to the primary/metastatic site and biologic characterizations of the tumor do not seem to be prognostically important in advanced cancer $^{10-14}$ that matched our study results.
Using the PPS, only about $10 \%$ of patients with a score of $50 \%$ or less would be expected to survive more than 6 months ${ }^{15}$. Performance status ${ }^{10,16,17}$ and various indices of activity and functional autonomy ${ }^{13,18}$ are prognostically significant. In particular, low performance status is considered a reliable prognostic factor to predict short-term survival. There is significant evidence of the prognostic importance of dyspnea ${ }^{10,16,17}$ and delirium or cognitive impairment ${ }^{17,19}$.

The current study showed that PPS of $>60 \%$, $30-50 \%$ and $10-20 \%$ had median survivals of $189.5,97$, 62 days compared to 50-90, 8-50 and 7-16 days in other studies ${ }^{20,21}$. 
Cases with dyspnea at rest and delirium in current study had median survival of 77 and 76.5 days compared to less than 30 and 38 days, respectively in other studies $^{20,21}$.

PPI split patients into three subgroups based on PPI score. Group 1 corresponded to patients of low PPI $<4$ with median survival of 107 days. Group 2 of intermediate PPI $>4$ and $<6$ with median survival of 103.5 days and Group 3 of high PPI $>6$ with median survival of 77 days, compared to 68, 21 and 5 days of corresponding groups, respectively as reported by Stone and colleagues ${ }^{4}$. Current study showed that median survival according to PPI was higher than other studies which could be attributed to relatively earlier referral of Egyptian advanced cancer patients to palliative care unit without exhausting patients with several lines of palliative chemotherapy or cancer modifying treatment.

With PPI (cut-off 4), current study showed that survival $<6$ weeks had sensitivity, specificity of $81.3 \%$ and $60.7 \%$ that matched Morita' results ${ }^{6}$, however it was $63 \%$ and $92 \%$, respectively in Stone' study ${ }^{4}$. Using a PPI of $>4$ as a cut-off, 6-week survival was predicted with a positive predictive value (PPV) of 0.28 and a negative predictive value (NPV) of 0.94 compared to 0.83 and 0.71 in Morita's research 6 , while $91 \%$ and $64 \%$, respectively in Stone's study ${ }^{4}$.

It was proposed that PPI had a number of potential advantages as ease of use, reliability and breadth of validity. It can be applied to patients with cancer in hospital, in hospice and at home.

It may be used by general physicians to achieve prognostic accuracy comparable, if not superior, to that of physicians experienced in oncology and palliative care and by oncology and palliative care specialists, to improve the accuracy of their survival predictions. It appears to be more objective than other Palliative Prognostic Scores. However, clinicians completing the PPI are required to judge whether or not delirium is caused 'solely by a single medication' and is thus potentially reversible. Another limitation of the PPI is that, it is probably most suitable for prediction of short survival periods and less useful for patients with a longer prognosis.

The current study showed that dyspnea, PPS, delirium and PPI had statistical significant effect on median survival of terminal cancer cases, that matched other studies which reported that there is significant evidence of prognostic importance of dyspnea ${ }^{10,12-14}$ and delirium or cognitive impairment on survival ${ }^{11,19}$. However analyzing the current study data with estimation of positive predictive, negative predictive values and odds ratios revealed that dyspnea and PPI (cut off 4) had statistical significant effect on 3 and 6-weeks survivals, while PPS with cut off $30 \%$ had significant effect only on 6-weeks survival. Our conclusion might not be applicable to other populations with different malignancies as the study was done on a group of patients admitted to specific oncology palliative care unit.

\section{CONCLUSION}

The study showed that dyspnea, PPS and PPI had significant predictive effect on survival of palliative patients with advanced malignancy. Larger prospective studies on different populations are needed to establish more accurate clinical predictors of survival of terminally ill cancer patients.

\section{REFERENCES}

1. Lamont EB, Christakis NA. Complexities in prognostication in advanced cancer: "To help them live their lives the way they want to". JAMA $2003 \mathrm{Jul}$ 2;290(1):98-104.

2. Vigano A, Dorgan M, Buckingham J, Bruera E, Suarez Almazor ME. Survival prediction in terminal cancer patients: A systematic review of the medical literature. Palliat.Med. 2000 Sep;14(5):363-74.

3. Glare P, Christakis N. Predicting survival in patients with advanced disease. In: Doyle D, Hanks G, Cherny NI, Calman SK, editors. Oxford textbook of palliative medicine. 3rd ed. USA: Oxford University Press; 2003.

4. Stone CA, Tiernan E, Dooley BA. Prospective validation of the palliative prognostic index in patients with cancer. J.Pain Symptom Manage. 2008;35(6):617-22.

5. Maltoni M, Caraceni A, Brunelli C, Broeckaert B, Christakis N, Eychmueller S, et al. Prognostic factors in advanced cancer patients: Evidence-based clinical recommendations-a study by the Steering Committee of the European Association for Palliative Care. J.Clin. Oncol. 2005 Sep 1;23(25):6240-8.

6. Morita $\mathrm{T}$, Tsunoda J, Inoue $\mathrm{S}$, Chihara $\mathrm{S}$. The Palliative Prognostic Index: A scoring system for survival prediction of terminally ill cancer patients. Support.Care Cancer 1999 May;7(3):128-33.

7. Morita T, Tsunoda J, Inoue S, Chihara S. Improved accuracy of physicians' survival prediction for terminally ill cancer patients using the Palliative Prognostic Index. Palliat.Med. 2001 Sep;15(5):419-24.

8. Anderson F, Downing GM, Hill J, Casorso L, Lerch N. Palliative Performance Scale (PPS): A new tool. J.Palliat. Care 1996 Spring;12(1):5-11.

9. American Psychiatric Association. Diagnostic and Statistical Manual of Mental Disorders DSM-IV-TR. 4th ed.: American Psychiatric Press; 2000.

10. Maltoni M, Pirovano M, Scarpi E, Marinari M, Indelli 
M, Arnoldi E, et al. Prediction of survival of patients terminally ill with cancer. Results of an Italian prospective multicentric study. Cancer 1995 May 15;75(10):2613-22.

11. Forster LE, Lynn J. The use of physiologic measures and demographic variables to predict longevity among inpatient hospice applicants. Am.J.Hosp.Care 1989 MarApr;6(2):31-4.

12. Heyse Moore LH, Ross V, Mullee MA. How much of a problem is dyspnoea in advanced cancer? Palliat.Med. 1991;5:20-6.

13. Hardy JR, Turner R, Saunders M, A'Hern R. Prediction of survival in a hospital-based continuing care unit. Eur.J.Cancer 1994;30A(3):284-8.

14. Vitetta L, Kenner D, Kissane D, Sali A. Clinical outcomes in terminally ill patients admitted to hospice care: Diagnostic and therapeutic interventions. J.Palliat.Care 2001 Summer;17(2):69-77.

15. Morita T, Tsunoda J, Inoue S, Chihara S. Validity of the palliative performance scale from a survival perspective. J.Pain Symptom Manage. 1999 Jul;18(1):2-3.
16. Reuben DB, Mor V, Hiris J. Clinical symptoms and length of survival in patients with terminal cancer. Arch.Intern. Med. 1988 Jul;148(7):1586-91.

17. Morita $\mathrm{T}$, Tsunoda J, Inoue $\mathrm{S}$, Chihara $\mathrm{S}$. Survival prediction of terminally ill cancer patients by clinical symptoms: Development of a simple indicator. Jpn.J.Clin. Oncol. 1999 Mar;29(3):156-9.

18. Faris M. Clinical estimation of survival and impact of other prognostic factors on terminally ill cancer patients in Oman. Support.Care Cancer 2003 Jan;11(1):30-4.

19. Rodrigus $P$, de Brouwer P, Raaymakers E. Brain metastases and non-small cell lung cancer. Prognostic factors and correlation with survival after irradiation. Lung Cancer 2001 May;32(2):129-36.

20. Vigano A, Dorgan M, Bruera E, Suarez Almazor ME. The relative accuracy of the clinical estimation of the duration of life for patients with end of life cancer. Cancer $1999 \mathrm{Jul}$ 1;86(1):170-6.

21. Scotto J, Schneiderman MA. Predicting survival in terminal cancer. Br.Med.J. 1972 Oct 7;4(5831):50. 